\title{
Promoting Campus Mental Health Literacy
}

\author{
Nsereko ND ${ }^{1 *}$ and Basa $V^{2}$ \\ ${ }^{1}$ Nkumba University, Uganda \\ 2International Society of Counselling and Clinical Supervisors, Basa Education and \\ Counselling Services Pty Ltd, Australia
}

*Corresponding author: Norman David Nsereko, Nkumba University, Uganda, Tel:

\section{Mini Review}

Volume 1 Issue 1

Received Date: August 09, 2017

Published Date: August 21, 2017

DOI: $10.23880 / \mathrm{mhrij}-16000105$

256703335948; E-mail: nserekon@gmail.com

Keywords: Mental Health; Suicide; Psychosocial; Mental disorders; Mental Health Literacy

\section{Introduction}

Mental health service provision, service utilization and supervision are hinged on mental health literacy in the effort to promote mental health wellbeing of an individual or a given community. This article examines the facets of university mental health wellbeing and the loopholes in the annual status reports of the National Council for Higher Education in Uganda that neglect the aspect of the institutions' mental health. Mental health literacy level is suggested as a central variable that may explain why evidence of campus mental health status is ignored. The article reiterates the need to report campus mental health status as an avenue to promote mental literacy on university campuses and for the general public in order to enhance mental health wellbeing.

\section{Foundation for Health and Resilience: Mental Health Literacy}

The growing need to address increasing mental health difficulties the world over and on university campuses [1] cannot be overemphasized because of the burdens they impose on individuals and the economy [2]. Whereas Dutch (2017) [2] makes strong arguments for investment in the prevention and treatment of mental disorders per se for the enhancement of overall health, quality of life and resilience, we argue that mental health literacy is at centre stage as the foundation stone to realize these existential concerns. This paper, thus creates a clarion call to address the need to raise mental health literacy in the public and specifically on university campuses mainly because mental health literacy on the part of the consumer influences utilization and service quality that ultimately affect the quality of their health and life [3].

Mental health literacy is a term coined by Jorm, et al. (1997) [4] and defined as "knowledge and beliefs about mental disorders which aid their recognition, management or prevention"p.183. Jorm (2000) [5] has observed that mental health literacy is an area which is comparatively neglected unlike the health literacy for physical health. He notes that many members of the general public cannot correctly recognize specific disorders or different types of psychological distress and they also differ from mental health experts in their beliefs about the causes of mental health disorders and the most effective treatments. He also observes that attitudes that hinder recognition and appropriate help-seeking are common. This affects all facets of conducting a desired mental health wellbeing that stretches from awareness, provision of the services, supervision and their utilization to continued effective functioning [6].

\section{The Third Force in Mental Health Promotion}

Following an existential intersectoral approach to address mental health needs through institutions of learning [7] and the mental health infrastructure, a 


\section{Mental Health \& Human Resilience International Journal}

solution to counter mental health difficulties seems to be a long way due to observed increasing mental health vulnerabilities. A third force to join in this struggle is being suggested. The Bodies or Councils that have an overall legislative mandate over institutions of learning would play a larger and effective role through mental health literacy promotion as part of a range of effective public mental health interventions to stimulate mental wellbeing and prevent mental disorders [8]. These organs, though outside the health sector can influence mental health outcomes through their periodical reports on university affairs by devoting a section to the mental status of universities under their jurisdiction and make it conditionality for university licensure, charter protocols and progress evaluations. This would contribute immensely to raising the level of mental health literacy for the institutions of learning and the general public.

\section{Evidence of Mental Health Difficulties and Concequences}

Concerns about Ugandan universities mental health status have been documented. German and Arya (1969) [9] indicated the prevalence of psychoneurotic illnesses among the undergraduate students at Makerere University. The report continued to reveal an interesting phenomenon that psychiatric illness at Makerere University (10.8\%) does not appear to be different widely from experiences of British and American Universities (Edinburgh $11.6 \%$, Belfast, 10.2\%). Thirty seven years after the report, Ovuga, Boardman \& Wasserman (2006) [10] observed that "there is little information on the current mental health of university students in Uganda," p.51, and they also pointed out the urgent need to provide mental health promotional services at the university. Campus suicide is prevalent and occurs for number reasons that range from low self- esteem, academic failures, relationship issues etc. [11]. A study on a representative sample of universities in Uganda indicated that $37 \%$ of students had symptoms of psychosocial problems [12] while $34.8 \%$ had symptoms of psychopathology in terms of depression and anxiety [13].

University mental health status is a touchy issue. Today universities are no longer associated with the proverbial notion of carefree time of the 60's and 70's where Gaterly (2005) [14] notes that the biggest worries were passing finals and finding a date. Today they are looked at as cauldrons of pervasive, rampart mental illness. Senator Gordon H. Smith of Oregon, USA in a News Release (2004) [15] observed that some students find college to be a pressured and painful time and that without the right kind of help, the depressed and hurting are too often unable to move past their feelings of darkness and hopelessness.

Studies done on the different mental health problems affecting students [12,16-19] indicate significant implications for the students' lives, academic performance and behaviour. For instance, anxiety may affect the student's ability to retrieve the information he /she learned the previous night. If depression goes untreated it can diminish prolonged cognitive functioning. Lack of mental health services to vulnerable students lead to continued mental disability and even ending up in justice system. Therefore Institutions of learning and other concerned bodies ought to play a significant role in addressing existing mental health issues [7,20,21].

\section{Ignored Campus Mental Health Reporting}

Mental health impacts many policy areas when it unfolds in significant proportion of the disease burden, in significant loss of work days leading to decreased productivity, causing significant individual and family suffering, which impacts negatively also on students' academic outcomes [8]. A supportive and mental health literate central university leadership is critical in promoting comprehensive and systemic changes that would reflect the nature of advocacy, planning, and intervention in mental health issues that would trickle down to deserving students to build literacy capacity to utilize available mental health services.

Mental health literacy among Legislative Bodies/Councils, university administrators in its effect on the promotion and utilization of mental health services on campuses is an area that remains poorly understood. This is rather evidenced in the exclusive emphasis on nonhealth policy areas in the existing annual reports on issues such enrolment, existing academic programs and their relevance, research and publications, academic staff and infrastructure, education facilities, financing of higher education and governance. A case study on Uganda campuses supports this assertion.

Every year the National Council for Higher Education (NCHE) a statutory body to legislate on Uganda higher education produces its report on "The state of higher education and training in Uganda:" [22]. The reports exam all possible factors that explain the success and challenges encountered in higher institutions of learning. However they fall short of considering mental health status on the campuses as a factor that might explain the failure to 


\section{Mental Health \& Human Resilience International Journal}

realize the environment conducive to learning and curbing the increasing disruptive behaviours observed on the campuses [10-12]. And neither do the reports include mental health issues among their recommendations to improve the delivery of quality higher education. This is rather an important omission while evaluating the state of higher education in Uganda.

In its jurisdiction, the Council oversees more than 49 universities, and 150,000 students and staff and sets up minimum standards for licensing and chartering of universities [23]. Every student pays an annual statutory fee to the Council.

Stakeholders of both licensed and chartered universities believe that universities play a designated role of serving in loco parentis for student health and safety [24]. They would be interested to know beyond the material, student/staff population and academic issues etc. being reported. Equally important the interests would cover the mental health infrastructure that include but not limited to campus mental health related status, budget for mental health, existing service provisions, facilities and programs that address suicide issues and students with drug, alcohol problems, the existing mental health service workers proportionate to students' population and their qualifications and on- going refresher training for the health workers and university mental health policy and supervision of the mental health workers. The latter takes central stage in ensuring professional management of the counseling services [6].

Notwithstanding the fact that professional counseling services are just a new phenomenon in Uganda [25], it is not surprising that mental health literacy and mental health services are still least contemplated for the most deserving vulnerable individuals including the entire university communities. Evidently, the public tends to label as mental illnesses in situations when a patient manifests severe psychiatric symptoms like bizarre or violent behaviours. These are looked at as chronic with far reaching consequences in one's functioning in life and need medical intervention [26-29]. Such a situation concurs with overwhelming recent surveys that have established that large sections of the public have a low mental health literacy which is reflected in a lack of knowledge about symptoms of mental disorders, meaning of psychiatric terms, and the effectiveness of various mode of treatment [30-32].

While mental health literacy is being championed for campus consumption through the National Council for
Higher Education in Uganda as a factor to promote mental health wellbeing to enhance quality higher education, it still remains an existential challenge to the central policy makers responsible for higher education. Mental health literacy levels among university policy makers may explain the lack of thrust to come out boldly on mental health issues in their reports. This makes a case to National Council for Higher Education, individual university administration that paying particular attention in their reports to the issues of mental health on university campuses, the long way to promote of mental health literacy on campuses is envisaged.

\section{Conclusion}

The realities of predisposition to mental health difficulties among the public and more so in the students, lack of adequate information on the current mental health on universities in Uganda and the novelty of the counseling field in Uganda are strong assumptions that mental health service provision and utilization in universities are still very challenging issues. If mental health is to be improved and appropriate intervention sought with emphasis on campuses, the level of mental health literacy needs to be raised. It therefore calls for the third factor namely the legislative Bodies /Councils (e.g. the Uganda National Council of Higher Education, NCHE) over universities to join in the mental health literacy landscape through their annual reports to include the status of university mental health and innovate it as a modus operandi for university licensure, charter acquisition and performance evaluation.

\section{References}

1. Hunt J, Eisenberg D (2010) Mental health problems and help-seeking behavior among college students. J Adolesc Health 46(1): 3-10.

2. Dutch D (2017) Growing Problem of Mental Disorders.

3. Smith RB, Armstrong M, Davis C (2006) The effect of health knowledge and literacy on utilisation, cost, service quality, and quality of life in children and adult Medicaid Mental Consumers. Tampa FL: Louis de la Parte Florida Mental Health Institute. University of South Florida, 1-38.

4. Jorm AF, Korten AE, Jacomb PA, Christensen $\mathrm{H}$, Rodgers B, et al. (1997) 'Mental health Literacy': a survey of the public's ability to recognize mental 


\section{Mental Health \& Human Resilience International Journal}

disorders and their beliefs about the effectiveness of treatment. Med J Aust 166(4): 182-186.

5. Jorm AF (2000) Mental Health Literacy: public knowledge and beliefs about mental disorders. Br J Psychiatry 177: 396-401.

6. Basa V (2017) Models of supervision in therapy, brief defining features. European Journal of Counselling Theory, Research and Practice 1(4): 1-5.

7. Rones M, Hoagwood K (2004) School-based mental health services: A research review. Clinical Child and Family Psychology Review 3(4): 223-241.

8. Sillanaukee P (2017) Promoting mental health.

9. German GA, Arya OP (1969) Psychiatric Morbidity amongst a Uganda Student Population. Br J Psychiatry 115(528): 1323-1329.

10. Ovuga E, Boardman J, Wasserman D (2006) Undergraduate student mental health at Makerere University, Uganda. World Psychiatry 5(1): 51-52.

11. Nsereko DN (2014) Evaluating psychosocial problems among university students in Uganda: Scale development and validation. Unpublished doctoral thesis, Nkumba University, Entebbe.

12. Nsereko DN, Musisi S, Nakigudde J, Holtzman S (2014a) Prevalence, types, distribution and associations of psychosocial problems among university students in Uganda. International Journal of Research Studies in Psychology 3(4): 3-16.

13. Nsereko DN, Musisi S, Nakigudde J, Ssekiwu D (2014b) Psychosocial problems and development of psychopathology among Ugandan university students. International Journal of Research Studies in Psychology 3(3): 3-16.

14. Gaterly G (2005) Colleges target mental health. Globe Newspaper.

15. Senator Gordon H (2004) Smith of Oregon, USA in a News Release.

16. Gallanger R (2002) National survey of counselling center directors. Alexandria, VA: International Association of Counselling Services, Inc, pp: 46.

17. Wechsler H, Lee JE, Kuo M, Lee H (2000) College binge drinking in the 1990s: A continuing problem:
Results of the Harvard School of Public Health 1999 College Alcohol Study. J Am Coll Health 48(5): 199210.

18. Haines ME, Norris MP, Kashy DA (1996) The effects of depressed mood on academic performance in college students. Journal of college Student Development 37(5): 519-526.

19. Spence SH, Duri V, Roeder U (1996) Performance realism in text-anxious students. Anxiety Stress and Coping 9(4): 339-355.

20. Zwaanswijk M, Verhaak PF, Bensing JM, van der Ende J, Verhulst FC (2003) Help seeking for emotional and behavioural problems in children and adolescents: A review of recent literature. Eur Child Adolesc Psychiatry 12(4): 153-161.

21. Evans DL, Foa EB, Gur RE, Hendin H, O'Brien CP, et al. (2005) Treating and Preventing Adolescent Mental Disorders. New York: Oxford University Press.

22. State of Higher Education, Uganda National Council of Higher Education reports: 2005, 2006, 2010, 2011, 2013, 2014.

23. National Council of Higher Education (2016) Accredited Academic Programs of Universities and Other Tertiary Institutions in Financial Year 2015/2016.

24. Stone G (2008) Mental health policy in higher education. The Counseling Psychologist 36(3): 490498.

25. Achieng O (2006) "Challenges of professional counselling in Uganda: An overview". A paper given at the annual conference for Uganda Counselling Association.

26. Abbo C, Ekblad S, Waako P, Okello E, Musisi S (2009) The prevalence and severity of mental illnesses handled by traditional healers in two districts in Uganda. Afr Health Sci 9(1): 16-22.

27. Gray AJ (2002) Stigma in psychiatry. J R Soc Med 95(2): 72-76.

28. Prior L, Wood F, Lewis G, Pill R (2003) Stigma revisited, disclosure of personal problems in primary care consultations in Wales. Social Science and Medicine 56(10): 2191-2200. 


\section{Mental Health \& Human Resilience International Journal}

29. Mental Literacy in Canada: Phase One Report Mental Health Literacy Project (2007).

30. Davis CS, Massey OT, Smith RB, Armstrong M, Vergon KS, et al. (2008) Refinement of an Instrument to Measure Mental Health Literacy and Examination of Interventions to Enhance Mental Health Literacy. (Agency for Health Care Administration (AHCA) series, 220-113). Tampa, FL: University of South Florida, Louis de la Parte Mental Health Institute, pp: 44.
31. Foster S, Rollefson M, Doksum T, Noonan D, Robinson G (2005) School Mental Health Services in the United States, 2002-2003. DHHS Pub. No. (SMA) 05-4068. Rockville, MD: Center for Mental Health Services, Substance Abuse and Mental Health Services Administration, pp: 163.

32. Suicide Prevention Resource Center (2004) Promoting mental health and preventing suicide in college and university settings. Newton, MA: Education Development Center, Inc, pp: 33. 